\title{
Studies and Research on the Electrical Resistance of the Polyethylene Insulation Used for the Chemical Protection of the Steel Pipelines Intended for the Natural Gas Distribution
}

\author{
STEFAN MIHAI FILIP1*, RAZVAN GEORGE RIPEANU², EUGEN AVRIGEAN ${ }^{3}$ \\ ${ }^{1}$ E.ON Gas Distribution Romania S.A., 40 Rusciorului Str., 550112, Sibiu, Romania \\ ${ }^{2}$ University Petroleum-Gas of Ploiesti, 39 Bucuresti Blvd.,100680, Ploiesti, Romania \\ ${ }^{3}$ Lucian Blaga University, Faculty of Engineering, 10 Victoriei Blvd., 550024, Sibiu, Romania
}

\begin{abstract}
The paper aims to find solutions to some of the problems the staff operating the natural gas networks have to face, which are the low, medium and high pressure, and the corrosion of the steel pipelines. This metal corrosion can be dealt with by insulating itthrough various procedures, the latest being the different thickness polyethylene strips insulation. The goal of the paper is to observe the insulation areas on the pipeline which can be destroyed by mechanical factors during operation and the method of remedying these faults with high density polyethylene strips.
\end{abstract}

Keyword: insulation, polyethylene, electrochemical protection

Corrosion of metals has been an issue that will permanently attract attention because it represents a continuous loss of quality and quantity of metallic materials. The main goal is to reduce these negative effects by developing some simple and inexpensive technical solutions adapted to each situation [6].

The solution for reducing the corrosion of the main pipelines for the transport and the distribution of natural gas is to apply high density polythene insulation strips in order to protect them from interacting with the corrosive environment [8].

Our paper is focused on observing the phenomena of destruction of the insulations caused by external mechanical factors, being a laboratory simulation of the real life conditions.

\section{Experimental part}

The Current State of Research in the Field

The current norms in the field are applied for the requirements and the methodology of testing the polythene protection, be it extruded or molded for underground or underwater steel pipelines. The applicability refers to the normal performance $\mathrm{N}$ at operating temperatures of up to 50 degrees Celsius or under more particular operating conditions $\mathrm{S}$ of up to 70 degrees Celsius, as well as having a normal ( $\mathrm{n}$ ) or enhanced (v) layer thickness according to the standards provided by DIN 2448 and DIN 2458. All these help define the quality of the pipeline protection as such. Steel pipelines, according to these norms, are in their turn high quality steel networks $[3,4]$.

\section{$P E$ polyethylene; $B R$ - butyl rubber}

The purpose of this standard is to ensure that the polyethylene insulation provides adequate protection against mechanical, thermal and chemical damage during operation, transport and storage, as well as during installation. The pipes are insulated by extruding the plastic sleeves or by coating, or by polyethylene powder fusion. A $1 \mathrm{~mm}$ thick insulation is appropriate for the corrosion protection. A greater thickness will increase the mechanical resistance [5].

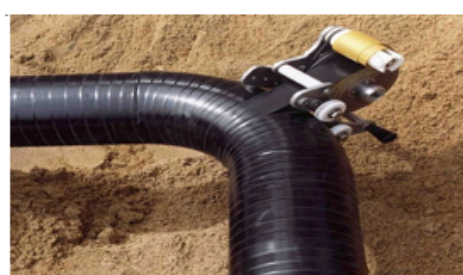

Fig.1. Insulation on bends with $P E+B R$ strips (the one strip system) and compensation for the diameter differences (reductions) (unevenness) with butyl rubber mastic (applicable on tees and tapping tees)

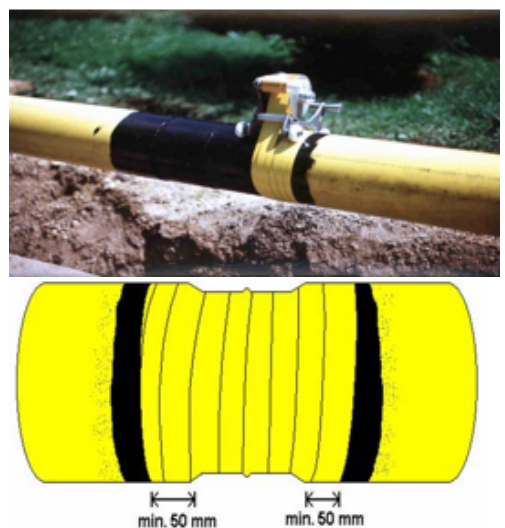

Fig.2. Seam welding (butt weld) insulated with PE +BR strips (the one strip system)

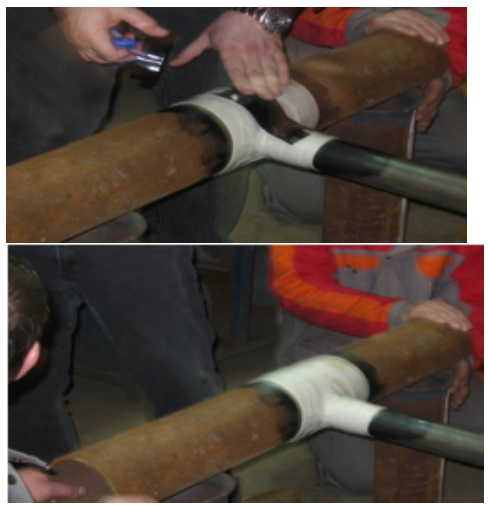

Fig. 3. Insulation on a tee (branch) with $\mathrm{PE}+\mathrm{BR}$ strips (the two-strip system) 


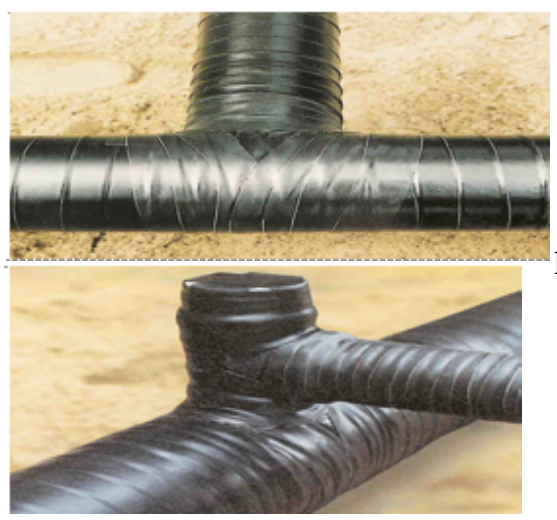

Fig. 4. Tee and tapping tee insulated with PE + BR strips (the twostrip system)

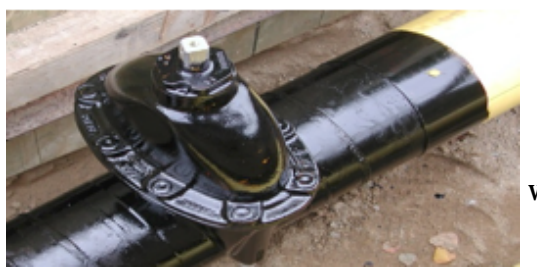

Fig. 5. Insulation of welding heads on the factory pre-insulated valve (no valve box) with surface operating rod

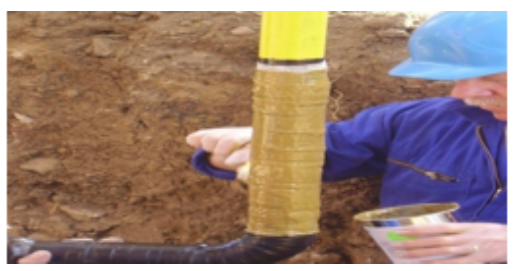

Fig.6. Insulation of underground/surface transition fitting

The characteristics mentioned herein were established as a result of a raise of the operating requirements (in terms of mechanical action and thermal stability) and because of the latest developments in polyethylene materials research. The S-type insulations must be used where the operating conditions involve high temperatures and where there are also important mechanical actions.

Determining the resistance to the formation of air bubbles is irrelevant because it does not occur when the insulating materials described here are used. Similarly, determining the cathodic unsoldering is not included because the tests would not provide relevant information on the quality of the polyethylene insulation and on the long term corrosion resistance. If it is required to determine the cathodic unsoldering, the ASTM G 8-90 American standard stipulates the use of the method described in DIN 30671. How ever, the values thus obtained are reproducible only under the specified conditions [7].

The Importance and the Necessity of Studying the Polyethylene Insulation - the Main Protection Factor for Steel Pipelines

After studying the existent literature, we have noticed that there are real solutions to achieve high quality insulations, considering the fact that all the steel pipelines used in the natural gas distribution must be protected by high quality insulations because the risk we are subjected to is very high, especially in the inhabited areas.

The experience acquired over the years thought us that the insulation was performed by authorized companies in the field, and the problems occurring both on pipes and on fittings were caused by blows on the insulated pipeline by accidental external factors like edgy rocks, excavator cups, etc., leading to faults in the insulation and corrosion of the pipeline [8].

\section{Conducting the experimental testings}

The electrical resistance of the insulation is dependent on several factors, including the nature and the thickness of the coating, the nature of the environment in which it performs its insulating function, the degree of degradation by the imprint of rigid bodies from the soil cover, etc.

The conducted experimental research observed the changes of the insulation resistivity due to the imprint of a spherical mandrel that simulated a stone acting on the insulation.

\section{Preparing the samples}

For carrying out the tests we made four sets of pipes with a $600 \mathrm{~mm}$ length, one coated with Fuchs extruded polyethylene, the other three with one, two and three layers of Xunda tape with a nominal thickness of $0.8 \mathrm{~mm}$ [10] (fig. 7). One set was maintained in the original condition, one was kept in rainwater for $72 \mathrm{~h}$ (fig. 8a), and one was kept in clayey sand for $72 \mathrm{~h}$ (fig. 8b).

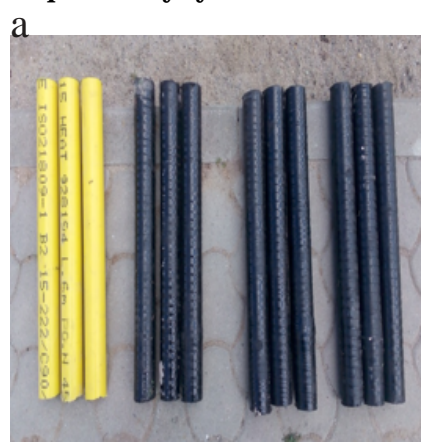

Fig. 7. Samples of insulated pipes prepared for testing (of one layer, two-layer or threelayer thickness)

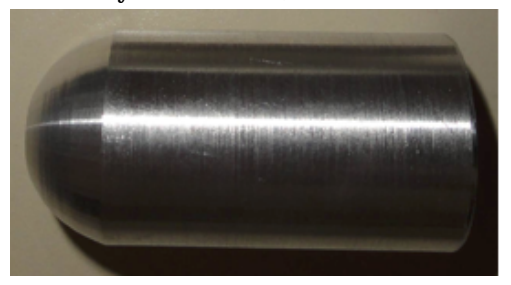

Fig. 9. Mandrel made of duraluminium

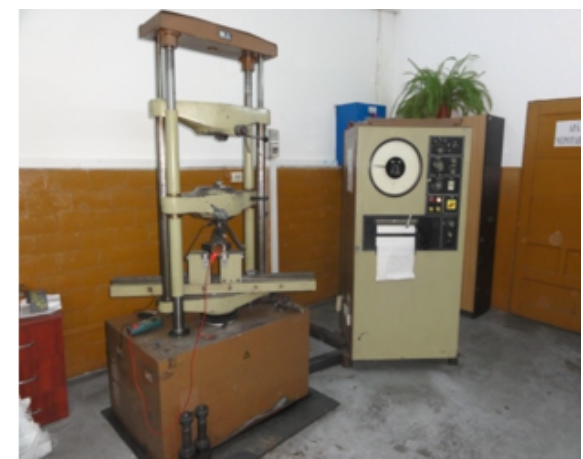

Fig.10. Tensile and compression testing machine
The local imprint compression action was conducted by means of a specially designed mandrel made of duraluminium (fig. 9) so as to act as a good electrical conductor and to have the necessary hardness for the application of forces of thousands of kgf.

The compression tests were performed in a specialized laboratory equipped with the appropriate machinery for conducting the physic-mechanical tests and analyses and non-distinctive controls, according to the European standards: [9]

-Tensile test Rn, Rpoy, A, Z -SR EN 10002-1:2002;

-Brinell hardness test -HBS-SR EN ISO 6506-1:2002;

-Bending test- SR ISO 7438:1993;

-Charpy impact test -KV-SR EN 10045-1:1993;

-Flattening test - SR EN 10233:1997.

The action of compression was applied through a special mandrel, as mentioned above, made of duraluminium, so 
as to be a good conductor and to have the hardness required for applying forces of thousands of kgf.

The testing method

The determination of the applied forces and the measurement of the insulation resistance after compression at various forces applied on the upper generator of the section of pipe are achieved by means of the machine shown below, (fig. 11).

As can be seen, different compression forces were applied on the pipe insulation by means of the testing machine, and by using the mega ohmmeter we determined the insulation resistance following its deterioration due to the application of the compression forces.

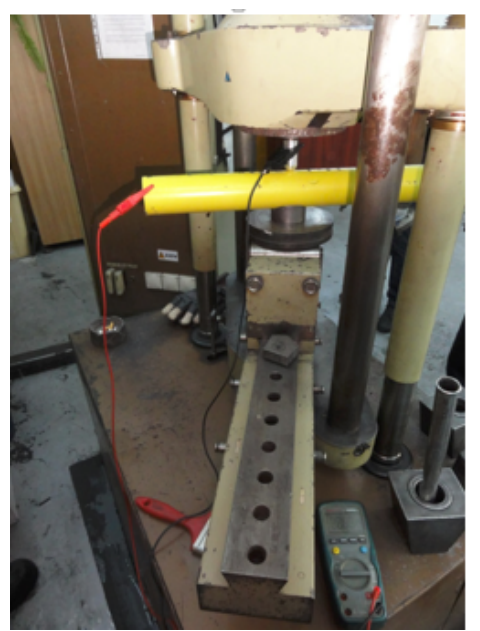

Fig.11. Detail of the installation for determining the insulation resistance

\section{Results and discussions}

As can be seen, the connections were made through the mandrel and the interior of the pipe, which we consider to be the most precise method of determining the insulation resistance. The data obtained from the measurements are presented in table 1.

Since the measurements were made by means of a machine that can only show values in the $\mathrm{M} \Omega \mathrm{m}$ scale, it was necessary to increase the load, thus reaching minimum values of $2,000 \mathrm{kgf}$, needed for determining the initial values of the cold-applied insulation resistance.

Also, we need to take into consideration the impossibility of maintaining the machine under constant load for more than 2 min and for this reason, the compression time was set at maximum 2 min, enough to read the insulation resistance in the point subjected to the compression forces, thus generating a deterioration of the applied insulation.

As can be seen from the values shown above, the force required for damaging the insulation applied by extrusion by the pipe manufacturer, in other words in the factory, is clearly higher than the cold applied one, even when there are more layers. Therefore, the first determinations of the resistance could be made, in the case of the extruded insulation, at a force value of $3,500 \mathrm{kgf}$, as compared to $2,000 \mathrm{kgf}$ in the case of the cold applied insulation.

Looking at the graphs shown below, comparing between the number of layers and the different environments, we conclude the following:

- subjected to a constant compression force, not through shocks, the ideal number of layers is at least two, further

Table 1

THE INSULATION RESISTANCE DEPENDING ON THE LOAD

\begin{tabular}{|c|c|c|c|c|c|c|c|c|c|}
\hline \multirow{3}{*}{ No. } & Applied force $[\mathrm{kgf}]$ & 2,000 & 2,500 & 3,000 & 3,500 & 4,000 & 4,500 & 5,000 & \multirow{2}{*}{$\begin{array}{c}\text { Penetration } \\
\text { force }\end{array}$} \\
\hline & \multirow[t]{2}{*}{ Time of constant compression on the load (min) } & 2 & 2 & 2 & 2 & 2 & 2 & 2 & \\
\hline & & \multicolumn{7}{|c|}{ Insulation resistance $[\mathrm{M} \Omega \mathrm{m}]$} & [kgf] \\
\hline 1 & PE cold insulated pipe -1 layer $(0.8 \mathrm{~mm})$ & 54.10 & 20.34 & 6.30 & 1.85 & 0.00 & 0.00 & 0.00 & 4,546 \\
\hline 2 & PE cold insulated pipe -2 layer $(1.6 \mathrm{~mm})$ & 56.87 & 31.10 & 7.08 & 1.60 & 0.00 & 0.00 & 0.00 & 4,600 \\
\hline 3 & PE cold insulated pipe -3 layer $(2.4 \mathrm{~mm})$ & 58.20 & 34.50 & 7.61 & 2.10 & 0.00 & 0.00 & 0.00 & 4,630 \\
\hline 4 & Fuchs insulated pipe & $\infty$ & $\infty$ & $\infty$ & 48.67 & 30.30 & 12.30 & 0.60 & 6,820 \\
\hline 5 & PE cold insulated pipe -1 layer $(0.8 \mathrm{~mm})$, kept in water for $72 \mathrm{~h}$ & 52.64 & 18.30 & 7.10 & 0.03 & 0.00 & 0.00 & 0.00 & 4,450 \\
\hline 6 & PE cold insulated pipe -2 layer ( $1.6 \mathrm{~mm})$, kept in water for $72 \mathrm{~h}$ & 53.28 & 22.47 & 4.01 & 0.55 & 0.00 & 0.00 & 0.00 & 4,550 \\
\hline 7 & PE cold insulated pipe -3 layer $(2.4 \mathrm{~mm})$, kept in water for $72 \mathrm{~h}$ & 53.10 & 21.30 & 6.70 & 0.83 & 0.00 & 0.00 & 0.00 & 4,630 \\
\hline 8 & Fuchs insulated pipe kept in water for $72 \mathrm{~h}$ & $\infty$ & $\infty$ & $\infty$ & 38.42 & 22.30 & 10.19 & 0.04 & 6,500 \\
\hline 9 & PE cold insulated pipe -1 layer $(0.8 \mathrm{~mm})$, kept in sand for $72 \mathrm{~h}$ & 54.30 & 27.62 & 10.02 & 3.80 & 0.00 & 0.00 & 0.00 & 3,530 \\
\hline 10 & PE cold insulated pipe -2 layer $(1.6 \mathrm{~mm})$, kept in sand for $72 \mathrm{~h}$ & 59.87 & 29.12 & 12.50 & 3.80 & 0.00 & 0.00 & 0.00 & 3,550 \\
\hline 11 & PE cold insulated pipe -3 layer $(2.4 \mathrm{~mm})$, kept in sand for $72 \mathrm{~h}$ & 60.20 & 29.80 & 11.70 & 3.87 & 0.00 & 0.00 & 0.00 & 3,650 \\
\hline 12 & Fuchs insulated pipe kept in sand for $72 \mathrm{~h}$ & $\infty$ & $\infty$ & $\infty$ & 58.27 & 20.26 & 5.86 & 0.03 & 6,600 \\
\hline
\end{tabular}

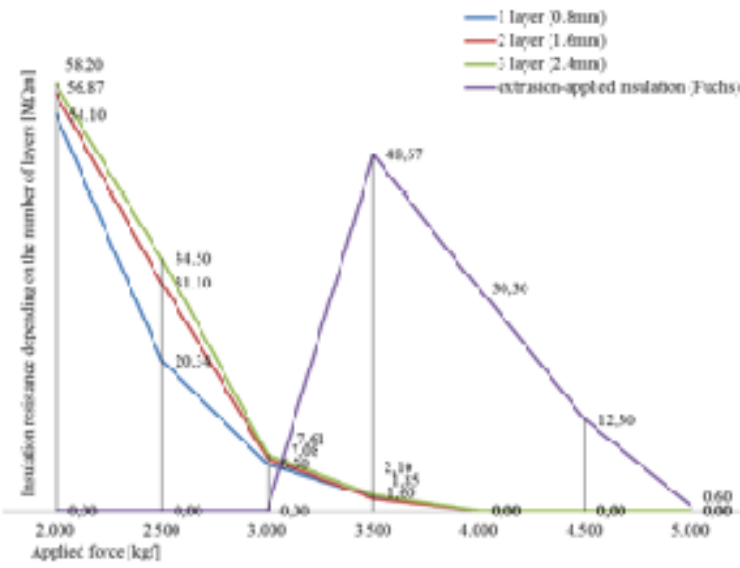

Fig.12. Distribution of the values of the resistance depending on the compression force

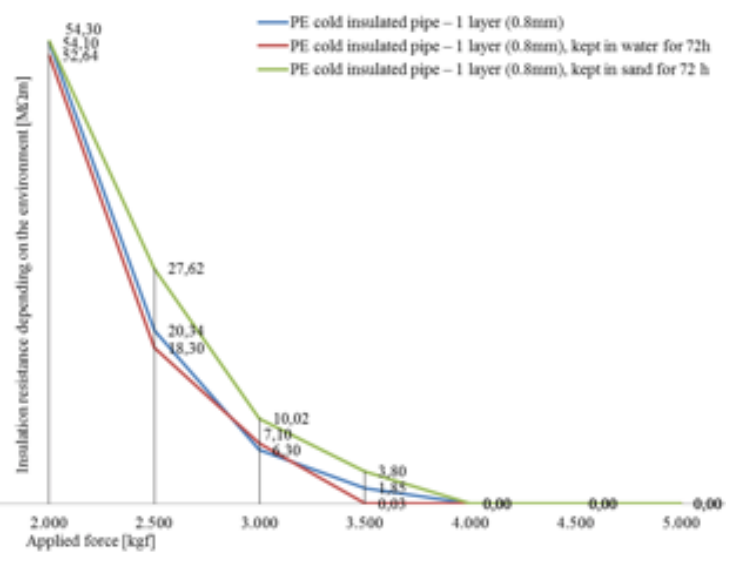

Fig.13. Influence of the pipeline laying environment 


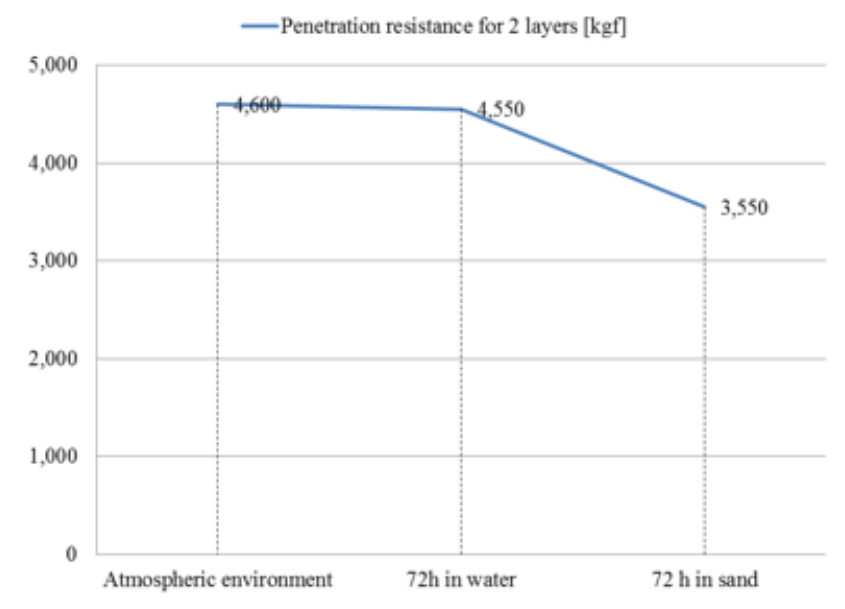

Fig.14. The penetration resistance of the insulation depending on the environment

perfecting with the supplementary application, (fig. 12 and 13);

- the force of penetrating the insulation is basically the same in the air and in the rainwater; however, it differs greatly, significantly decreasing, if the case of the sample kept in sand. This is due to the grain size and the hardness of the sand inside the pipe when applying the compression force and we can thus conclude that the deterioration of the insulation when there are sharp objects in the sand cover is accelerated by the sand layer between the insulation and the pipe, (fig. 14).

\section{Conclusions}

Following the conducted studies, it became clear how important it is to use high density polyethylene insulation on the steel pipelines used in natural gas transport and distribution. We presented certain aspects regarding the correct way of insulating the steel pipelines, and also several aspects of the breakage or the superficial deterioration of the insulation caused by external factors.

We presented the polyethylene insulation and subjected it to mechanical stains after it had been kept in various external environments which we frequently encounter in daily practice. These samples were studied for three layers (three $0.8 \mathrm{~mm}$ thicknesses) resulting that the insulation should have an optimal thickness, not necessarily a large number of layers, being known that the large number of layers implies considerable material and labor expenses.

As future objectives, we intend to conduct a study in the finite element field of this insulation, being important to support these experimental results and to develop an algorithm and a database. Also, there will be a number of meetings with the people in the industry in the future, in order to communicate them the results so that they could be taken into consideration.

\section{References}

1. AVRIGEAN, E., Study on Temperature Distribution in the J ointing Fittings for Polyethylene Natural Gas Pipes. 2015 3rd International Conference on Recent Trends in Materials and Mechanical Engineering (ICRTMME 2015), J anuary 15-16, 2015, Auckland, New Zealand.

2. AVRIGEAN, E. BONDREA, I., Theoretical and Experimental Comparative Study of Strains Acting on the Hub Fork of a Cardan J oint. The 2015 2nd International Conference on Advanced Materials, Structures and Mechanical Engineering (ICAMSME 2015), Incheon National University, South-Korea, May 29-31, 2015.

3. CHISALITA, D., Technical norms of corrosion protection of pipelines. Sibiu. 2007

4. ${ }^{* * *}$ Technical Standards of Design, Manufacture and Maintenance, Associated with Natural Gas Production / Storage Facilities, Gas. Romgaz Medias - 2015. Romgaz Medias-2015.

5. RIPEANU, R.G., METEA, V., PUPAZESCU, AL., Studies regarding soil induced stresses in buried steel gas pipes, Tribological Journal Bultrib, Publ House TU Sofia, Vol. III, 2013. Sofia, Bulgaria. 2013.

6. SOFONEA. G., et al. Constructive solutions for compensating the super-elevation of the DN 1200 gas transit pipeline, Isaccea Negru Voda, due to over passing the Taik stream, county Tulcea, Beneficiary: S.C. Transgaz S.A. Medias, Research Contract 27/2009.

7. TUDOR, I., OTHERS, Corrosion protection and rehabilitation of pipes and tanks. University Petroleum-Gas of Ploiesti. 2007.

8. TUDOR, I., RIPEANU, R.G., Corrosion engineering. vol. I @i II. University Petroleum-Gas of Ploiesti. 2002.

9. S.C. UPRUC CTR S.A. Fagaras. Specifications of testing laboratory equipment, http://www.uprucctr.com/ro/about-us.php

10. JINING XUNDA PIPE COATING MATERIALS CO.,LTD, Specification of Xunda en 12068 C 50 coating system, http://w ww.pipelinew raptape. com/XUNDA-en-12068-C-50-coating-system-p137.html

$\overline{\text { Manuscript received: } 27.09 .2016}$ 